\section{Developmental disturbances associated with agenesis of the permanent maxillary lateral incisor}

\author{
T. Pinho, ${ }^{1}$ P. Maciel ${ }^{2}$ and C. Pollmann ${ }^{3}$
}

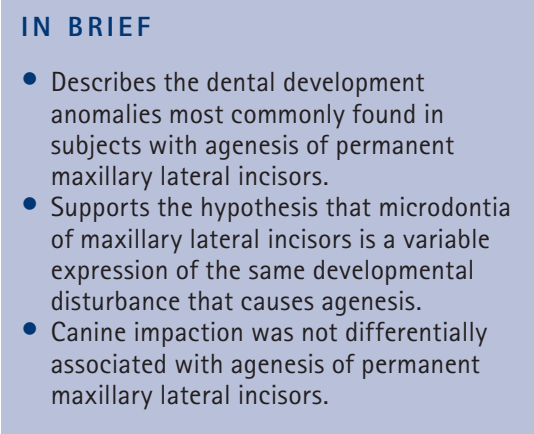
maxillary lateral incisors.

\begin{abstract}
The aim of this study was to characterise the intra and extra-oral phenotype associated with agenesis of the permanent maxillary lateral incisor. We compared three groups: (1) subjects with agenesis of one or both permanent maxillary lateral incisors ( $n=80)$; (2) first and second degree relatives of group 1 with no agenesis of the permanent maxillary lateral incisor and (3) subjects with no agenesis of the maxillary lateral incisor or family history of it $(n=49)$. For each of the 201 subjects detailed clinical information was reviewed and panoramic radiographs were analysed. Considering only the sample with unilateral agenesis, microdontia of the contralateral permanent maxillary lateral incisor was significantly more frequent in group 1 (82.4\%) than in group $2(25 \%)$ and the control group (2\%). This supports the theory that microdontia is a variable expression of the same developmental disturbance that causes tooth agenesis. The absence of third molars occurred more often in group 1 (36.2\%) than in groups 2 and 3 (18.6\% and 18.9\% respectively), confirming that agenesis of third molars was markedly associated with the agenesis of the permanent maxillary lateral incisor. Agenesis of teeth other than third molars was not significantly different among subjects with agenesis of the permanent maxillary lateral incisor and their relatives. The frequencies of supernumerary teeth, permanent maxillary canine impaction, general health condition and minor anomalies were not significantly different between the three groups.
\end{abstract}

\section{INTRODUCTION}

A tooth is defined to be congenitally missing if it has not erupted in the oral cavity and is not visible from radiography and has not been extracted or accidentally lost. Congenital lack of a tooth (hypodontia) results from a disturbance during the early stages of tooth development. Hypodontia is relatively frequent in the permanent dentition, with a reported incidence of between 3.5\% and 8.8\%, excluding third molars, and higher values if considering the third molars. ${ }^{1-11}$ It is also more frequently observed in females, although differences in gender distribution have been reported among populations. ${ }^{1,5,6,10,12-14}$

\footnotetext{
${ }^{*}$ Centro de Investigação Ciências da Saúde (CICS), Instituto Superior de Ciências da Saúde-Norte/CESPU, Portugal; ${ }^{2}$ Life and Health Sciences Research Institute (ICVS), School of Health Sciences, University of Minho, Braga, Portugal; ${ }^{3}$ Faculty of Dental Medicine (FMDUP), Universidade do Porto, Portugal

*Correspondence to: Teresa Pinho, Centro de Investigação Ciências da Saúde (CICS), Instituto Superior de Ciências da Saúde-Norte/CESPU, Rua Central de Gandra, 1317, 4585-116 Gandra, PRD, Portugal Email: teresa.pinho@iscsn.cespu.pt
}

\section{Online article number E25}

Refereed Paper - accepted 22 June 2009

DOI: $10.1038 /$ sj.bdj.2009.961

${ }^{\oplus}$ British Dental Journal 2009; 207: E25
Agenesis of the permanent maxillary lateral incisor is one of the most common disorders, although its frequency varies according to the population studied, $1,4,5,8,10,11,13,14$ with values ranging between $0.8 \%$ and $2 \%$ for the permanent teeth, and between $0.1 \%$ and $0.7 \%$ for the primary teeth. In the Portuguese population, the prevalence of agenesis of the permanent maxillary lateral incisor is $1.3 \%$, with a slightly higher frequency in females. ${ }^{15}$

Among individuals with missing teeth, those who most frequently request treatment are those with missing maxillary anterior teeth, ${ }^{16}$ especially with agenesis of the permanent maxillary lateral incisor. ${ }^{17,18}$ Early diagnosis of missing teeth is not usual, although some direct or indirect signs and/or elements of the family history might indicate a problem. Hobkirk et al. ${ }^{19}$ reported that in 451 patients treated for hypodontia, more than 50\% were older than 12 years; they also found a low rate of importance given to this problem either by the patients, parents or their dental practitioners; the cases of early diagnosis resulted from casual observation or family history.
Objective examination is essential for the diagnosis of hypodontia of permanent teeth and some clinical signs are: attrition, ankylosis, infra-occlusion, persistence and/or asymmetrical loss of primary teeth, tooth migration, overeruption of the permanent antagonists, diastemas and microdontia.,20,23 Radiographs must be taken to confirm the diagnosis, especially the dental panoramic radiography, as suggested by Pilo et al., ${ }^{9}$ for an early diagnostic procedure in patients younger than eight years. ${ }^{19,20}$

According to Garn and Lewis, ${ }^{24}$ the crown size reduction associated with congenitally missing teeth is more significant in multiple agenesis than in the agenesis of a third molar, occurring more frequently in women. Schalk-Van-DerWide et al. ${ }^{25}$ observed that patients with oligodontia (more than six instances of agenesis) had a reduction of both mesiodistal and labio-lingual dimensions of the tooth crowns. The reduction in size of some teeth in relatives may be an important factor for the determination of familiar occurrence of missing teeth. ${ }^{26}$ Baum and Cohen ${ }^{27}$ stated that the factors 
involved in third molar agenesis and of other teeth are the same.

The paradoxical frequency of a malpositioned maxillary permanent canine in the case of agenesis or microdontia of the permanent maxillary lateral incisor shows the importance that these teeth have as 'the guiding tooth' of the eruption path of the canine. According to some authors, 2,28,30 in order to achieve an early diagnosis of impacted canines, one should take into consideration the importance of the root of the permanent maxillary lateral incisor in the eruption of the canine tooth. Some authors suggest ${ }^{29,31}$ that these two phenomena might involve the same or similar genetic factors. In contrast, Brenchley and Oliver $^{32}$ did not observe any association between ectopic maxillary canines and agenesis or microdontia of the permanent maxillary lateral incisor. However, they found a correlation with Class II Div 2 malocclusion, probably due to the displacement of the adjacent permanent maxillary lateral incisor.

The simultaneous occurrence of agenesis and supernumerary teeth is uncommon ${ }^{33,35}$ and it is more frequent in the permanent than the primary dentition. ${ }^{33}$

In some syndromes there are typical patterns of hypodontia, while in others the congenital reduction in teeth number is described as sporadic. Anodontia (congenital absence of teeth) is rare, ${ }^{36}$ and is often associated with ectodermal dysplasia. ${ }^{37}$

Hypohidrotic ectodermic dysplasia is the most common form of ectodermic dysplasia in humans and is estimated to affect at least 1 in 17,000. Most people with hypohidrotic ectodermic dysplasia have hypohidrosis, hypotricosis and teeth that are agenesis or malformed. ${ }^{37,39}$ There are other syndromes like Rieger's syndrome where hypodontia is a main feature too. ${ }^{40}$ For Schalk Van Der Weide et al., ${ }^{41}$ the patients with oligodontia/I (isolated) showed a low degree of association of extra-oral signs and with combinations of just one or two ectodermic anomalies. On the contrary, patients with oligodontia/S (Syndrome) show a strong tendency to present a combination of three or more ectodermic anomalies.

The purpose of this retrospective study was to investigate intra-oral and some general anomalies associated with agenesis of the permanent maxillary lateral incisor in order to find alert signals associated to this feature.

\section{MATERIAL AND METHODS}

The study sample included 201 subjects aged between nine and 76 years, divided into three groups: (1) subjects congenitally missing one or both permanent maxillary lateral incisor, from the clinical files of the ISCSN (Instituto Superior de Ciências da Saúde Norte, Portugal) ( $\mathrm{n}=80)$; (2) first and second degree relatives of the patients in group 1 ( $n=72$ ); (3) control group with no agenesis of the permanent maxillary lateral incisor, randomly selected among the general clinical patients of the ISCSN $(n=49)$.

A dental panoramic radiograph and a detailed clinical file were analysed for all subjects. Children under nine years of age were excluded from all groups, as the radiographic study for some dental germs could be inconclusive. ${ }^{1}$

Among other anomalies, we investigated (i) microdontia of the contralateral permanent maxillary lateral incisor (in group 1, only the unilateral agenesis of permanent maxillary lateral incisor cases $[\mathrm{n}=$ 34] could be considered), (ii) agenesis of other teeth, (iii) supernumerary teeth, (iv) impacted maxillary permanent canine, (v) dental transposition and (vi) the presence of minor malformations.

The criteria for the classification of microdontia followed Proffit's terminology: ${ }^{42}$ a permanent maxillary lateral incisor is considered microdontic when its mesiodistal dimension is inferior to that of the mandibular permanent lateral incisor. These teeth are defined as conical in shape due to the narrowing of the crown's diameter from the cervical to the incisor area. ${ }^{2}$

The data collected from the dental panoramic radiographs included agenesis of teeth other than the permanent maxillary lateral incisor which was also revealed through clinical examination and confirmed by history.

In addition, general examinations of all 201 individuals included evaluation of anomalies of ectodermic derived structures such as skin, nails, hair, face, eyes and ears, normally referred to as minor abnormalities.

In order to study the absence of the third molar and the impaction of maxillary canine or dental transpositions, we performed an analysis excluding subjects aged below 15 years in all of the groups. Previous studies ${ }^{43}$ refer to this age as being the approximate age limit when a non-erupted canine tooth can be considered to be impacted; others state this age as a limit to the appearance of the third molar germs. ${ }^{44,45}$ Therefore, the sample size of this part of the study was reduced to $n=160$ (group 1: $n=63$, group $2: n=60$ and group $3: n=37$ ).

Statistical analysis was performed on all data using the chi-squared test to compare non-continuous variables. Differences were considered statistically significant for $\mathrm{p}<0.05$.

All the participants gave written informed consent for participation in this study, which was approved by the ethics committee of the Faculty of Dental Medicine of the University of Porto.

\section{RESULTS}

\section{Sample analysis}

In group $1(\mathrm{n}=80)$ there were $46(57.5 \%)$ subjects with bilateral agenesis of the permanent maxillary lateral incisor and 34 $(42.5 \%)$ with unilateral agenesis of the permanent maxillary lateral incisor. From these 34 subjects, 20 (34\%) were missing the right lateral incisor and 14 (17.5\%) the left lateral incisor. Ages ranged from nine to 76 years (average $26.01 \pm 14.32$ ). Fiftyfour $(67.5 \%)$ were female and 26 (32.5\%) were male.

In group $2(\mathrm{n}=72)$ ages ranged from nine to 75 years (average $29.7 \pm 14.5$ ). Thirty-nine (54.2\%) were female, while $33(45.8 \%)$ were male.

In group $3(\mathrm{n}=49)$ ages ranged from nine to 64 years (average $20.6 \pm 8.2$ ). Twenty-three (46.9\%) were female and 26 (53.1\%) were male.

\section{Microdontia of the permanent maxillary lateral incisor}

Group 1 had 46 cases of bilateral absence, therefore the sample used to calculate the frequency of contralateral microdontia was limited to the 34 cases with unilateral absence. This limitation did not occur in groups 2 and 3.

Microdontia of the contralateral incisor (Table 1) was found in 28 cases $(82.4 \%)$ in group 1: $12(35.3 \%)$ on the right side and 16 (47.1\%) on the left side. In group 2, only 25\% had lateral incisor 
Table 1 Frequency of permanent maxillary lateral incisor microdontia in group 1 individuals with unilateral agenesis, group 2 relatives of group 1 (with no agenesis) and group 3 the control group

\begin{tabular}{|c|c|c|c|c|c|c|}
\hline & & \multicolumn{5}{|c|}{ Maxillary lateral incisor MICRODONTIA } \\
\hline & & No & 12 and 22 & 12 & 22 & Total \\
\hline \multirow[t]{2}{*}{ Group 1} & $n$ & 6 & $-^{*}$ & 12 & 16 & 34 \\
\hline & $\%$ & $17.6 \%$ & & $35.3 \%$ & $47.1 \%$ & $100.0 \%$ \\
\hline \multirow[t]{2}{*}{ Group 2} & $n$ & 54 & 14 & 1 & 3 & 72 \\
\hline & $\%$ & $75.0 \%$ & $19.4 \%$ & $1.4 \%$ & $4.2 \%$ & $100.0 \%$ \\
\hline \multirow[t]{2}{*}{ Group 3} & $\mathrm{n}$ & 48 & 1 & 0 & 0 & 49 \\
\hline & $\%$ & $98.0 \%$ & $2.0 \%$ & $0 \%$ & $0 \%$ & $100.0 \%$ \\
\hline \multirow[t]{2}{*}{ Total } & $\mathrm{n}$ & 108 & 15 & 13 & 19 & 155 \\
\hline & $\%$ & $69.7 \%$ & $9.7 \%$ & $8.4 \%$ & $12.3 \%$ & $100.0 \%$ \\
\hline
\end{tabular}

Table 3 Frequency of other associated dental agenesis, excluding third molars in group 1 - individuals with unilateral agenesis, group 2 relatives of group 1 (with no agenesis) and group 3 the control group

\begin{tabular}{|l|l|l|l|l|}
\multicolumn{2}{c}{} & \multicolumn{3}{|l}{ Other associated dental agenesis, excluding third molars } \\
\cline { 2 - 5 } & yes & No & Total \\
\hline \multirow{2}{*}{ Group 1 } & $n$ & 8 & 72 & 80 \\
\hline \multirow{2}{*}{ Group 2 } & $\%$ & $10.0 \%$ & $90.0 \%$ & $100.0 \%$ \\
\hline \multirow{2}{*}{ Total } & $n$ & 4 & 68 & 72 \\
\cline { 2 - 5 } & $\%$ & $5.6 \%$ & $94.4 \%$ & $100.0 \%$ \\
\hline & $n$ & 12 & 140 & 152 \\
\hline & $\%$ & $7.9 \%$ & $92.1 \%$ & $100.0 \%$ \\
\hline
\end{tabular}

microdontia: $1.4 \%$ on the right side, $4.2 \%$ on the left side and $19.4 \%$ bilaterally. In group 3, only one case (2\%) of bilateral microdontia was found.

Microdontia was significantly more frequent in the group of individuals presenting agenesis of permanent maxillary lateral incisor $\left(\chi^{2}=113,6\right.$ [5 cells $(41.7 \%)$ have an expected count less than 5 . The minimum expected count is 2.85], $\mathrm{df}=6$, $\mathrm{p}<0.05$; chi-square test).

\section{Agenesis of other teeth (third molars excluded)}

Groups 1 and 2 included individuals with other dental ageneses (excluding third molars), the majority corresponding to the second premolars (Tables 2 and 3). The Fisher's exact test shows that there are no significant differences between these groups $\left(\chi^{2}=0.509, \mathrm{df}=1, \mathrm{p}>0.05\right)$ (Table $3)$. We found no other congenital absences in group 3.

\section{Supernumerary teeth}

In the 201 individuals selected, there were two patients with supernumerary teeth: one mesiodens (group 1) and one associated with an odontoma (group 2).

\section{Third molar agenesis}

In this part of the study all patients younger than 15 years were excluded from the sample. Out of the 160 individuals only 154 were included in this sub-analysis, due to the fact that six subjects did not remember whether or not they had had their third molars removed, five cases in group 1 and one case in group 2 (Table 4).

Third molar absence was significantly more frequent in group $1(36.2 \%)$ than in group 2 (18.6\%) and group 3 (18.9\%) ( $p=0.007$; chi-square test) (Table 5).

\section{Impacted maxillary canines}

Out of the 160 individuals 15 years or older, seven had impacted maxillary canines.
Table 2 Identification of other associated dental agenesis, excluding third molars,

in group 1 - individuals with unilateral agenesis and group 2 relatives of group 1 (with no agenesis)

\begin{tabular}{|l|l|l|}
\multicolumn{2}{|l|}{$\begin{array}{l}\text { Other associated dental } \\
\text { agenesis, excluding third molars }\end{array}$} & $\begin{array}{l}\text { Number } \\
\text { of cases }\end{array}$ \\
\hline Group 1 & 15,25 & 1 \\
\cline { 2 - 3 } & $15,25,35,45$ & 1 \\
\cline { 2 - 3 } & $16,26,35$ & 1 \\
\hline \multirow{4}{*}{} & 31 & 1 \\
\hline \multirow{2}{*}{ Group 2 } & 35 & 2 \\
\hline & 35,45 & 2 \\
\hline & 15 & 1 \\
\hline & $16,15,24,25,26,36,46$ & 1 \\
\hline & $25,15,25,26,35,45$ & 1 \\
\hline
\end{tabular}

Three in group $1(\mathrm{n}=63) 4.76 \%$, two in group $2(\mathrm{n}=60) 3.33 \%$ and two cases in group 3 ( $\mathrm{n}=37$ ) 5.40\%. The frequency of impacted maxillary canines was not significantly different between the groups ( $\mathrm{p}$ $=0.99$; chi-square test).

\section{Tooth transpositions}

Tooth transpositions were not found.

\section{Minor anomalies/clinical manifestations}

In the general examination, most of the individuals included in the three groups did not present any health problems (see Table 6 for a detailed description of the findings). Although minor anomalies were relatively frequent, there was no statistically significant difference in the frequency of minor anomalies and other clinical manifestations among the groups (group 1: 20\%; group $2=19.4 \%$; group $\left.3=20.4 \% ; \chi^{2}=0.018 \mathrm{df}=2, \mathrm{p}>0.05\right)$. of notice, one patient had a bifid uvula (group 1).

\section{DISCUSSION}

In this study, as in others ${ }^{5,13,15,46}$ some dental anomalies associated with agenesis of permanent maxillary lateral incisor were found. In accordance with Horowitz ${ }^{4}$ and Nieminen et al. ${ }^{47}$ we also found that microdontia of the lateral incisor was the most frequent associated tooth anomaly.

According to Arte et al. ${ }^{48}$ the prevalence of the superior lateral incisor's microdontia 


\begin{tabular}{|c|c|c|}
\hline & $\begin{array}{l}\text { Third molar } \\
\text { agenesis }\end{array}$ & $\begin{array}{l}\text { Number of } \\
\text { cases }\end{array}$ \\
\hline \multirow[t]{8}{*}{ Group 1} & 18 & 1 \\
\hline & 48 & 3 \\
\hline & 18,28 & 1 \\
\hline & 18,38 & 1 \\
\hline & 38,48 & 4 \\
\hline & $18,28,48$ & 1 \\
\hline & $18,38,48$ & 1 \\
\hline & $18,28,38,48$ & 9 \\
\hline \multirow[t]{7}{*}{ Group 2} & 18 & 1 \\
\hline & 28 & 1 \\
\hline & 48 & 1 \\
\hline & 28,48 & 1 \\
\hline & 38,48 & 3 \\
\hline & $18,28,48$ & 1 \\
\hline & $18,28,38,48$ & 3 \\
\hline \multirow[t]{6}{*}{ Group 3} & 18 & 1 \\
\hline & 28 & 1 \\
\hline & 48 & 2 \\
\hline & 18,28 & 1 \\
\hline & $18,38,48$ & 1 \\
\hline & $18,28,38,48$ & 1 \\
\hline
\end{tabular}

in first and second degree relatives is 9\% and $11 \%$ respectively. We compared the groups in order to investigate a potential familial aggregation of certain clinical features. The highest frequency of microdontia was found in the group missing one permanent maxillary lateral incisor. Their relatives also presented a higher frequency of this finding than the control group. These data point towards two conclusions: unilateral incisor agenesis is associated with lateral incisor microdontia; the frequency of microdontia is significantly higher in their relatives than in the control population, which may indicate a significant contribution of familial factors (genetic and/or environmental) to this trait.

These data are in agreement with the findings of Svinhufvud et al. ${ }^{49}$ and Baccetti, ${ }^{2}$ who have shown there is a reciprocal and

\begin{tabular}{|c|c|c|c|c|}
\hline & & \multicolumn{3}{|c|}{ Third molar agenesis (age 15 and over) } \\
\hline & & yes & No & Total \\
\hline \multirow[t]{2}{*}{ Group 1} & $n$ & 21 & 37 & 58 \\
\hline & $\%$ & $36.2 \%$ & $63.8 \%$ & $100.0 \%$ \\
\hline \multirow[t]{2}{*}{ Group 2} & $n$ & 11 & 48 & 59 \\
\hline & $\%$ & $18.6 \%$ & $81.4 \%$ & $100.0 \%$ \\
\hline \multirow[t]{2}{*}{ Group 3} & $n$ & 7 & 30 & 37 \\
\hline & $\%$ & $18.9 \%$ & $81.1 \%$ & $100.0 \%$ \\
\hline \multirow[t]{2}{*}{ Total } & $n$ & 39 & 115 & 154 \\
\hline & $\%$ & $25.3 \%$ & $74.7 \%$ & $100.0 \%$ \\
\hline
\end{tabular}

significant aetiological association between hypodontia, microdontia, malformation and lack of tooth development. Several authors ${ }^{47,49}$ propose that microdontia of one or more lateral incisor is a different phenotypic expression of the same genetic trait. Therefore, microdontia may, considering it potentially reveals a common aetiopathogenesis with agenesis of the permanent maxillary lateral incisor, become an important clinical marker of altered morphogenesis. This phenotypical expression may represent a bilaterally disturbed tissue interaction, resulting from a 'handicapped' genetic mechanism, which is also dependent on humoral and neighbouring cell signalling.

Interestingly, third molar agenesis was more frequent in group 1 ( $p=0.007$ ), in comparison with the other groups. This also suggests that common factors may be interfering with the morphogenesis of the permanent maxillary lateral incisor and of third molars. Some authors ${ }^{50}$ also suggest that the agenesis of third molars germs depends on the anteroposterior dimensions of the maxilla.

Agenesis of teeth other than third molars was not significantly different between subjects with congenitally missing permanent maxillary lateral incisors and their relatives.

It has been suggested that agenesis of the permanent maxillary lateral incisor may play a role in the impaction of maxillary canines; at least two theories have been proposed to explain this condition. The guidance eruption theory, proposing that displacement is caused by predisposing local factors, such as the absence or anomalies in the shape and in the size of the permanent maxillary lateral incisor, agenesis of the permanent maxillary lateral incisor, microdontia or the decreased size of the root of those teeth, are considered decisive mechanical factors for the deviation of the maxillary canines during their eruption..$^{28,31}$ The other theory points out that the genetic factors are the primary cause for both maxillary canine tooth displacement and absence or microdontia of the permanent maxillary lateral incisor and/or possibly other associated dental anomalies. ${ }^{49,51,52}$

Zirberman et al..$^{31}$ suggested that a strong association exists in the members of a family with regard to displaced canine teeth and anomalies (microdontia or agenesis) of the permanent maxillary lateral incisor. ${ }^{53}$ However, in the present study, no significant differences were found in the frequency of included maxillary canines among the three groups. This is in accordance with Brenchley and Oliver. ${ }^{32}$ The transposition of the maxillary canine has also been associated with microdontia and with agenesis of the permanent maxillary lateral incisor, $, 54,55$ but in this study not a single transposition occurred.

Only one case of 'hypodontia and concomitant hyperdontia'56 was found, confirming the rarity of this clinical entity. ${ }^{33,35}$

In the present investigation, the congenital absence of the first maxillary and mandibular molars was detected only in two patients that were relatives, and did not fit in any specific syndrome. 
Table 6 Identification of minor anomalies/ clinical manifestations

\begin{tabular}{|c|c|c|}
\hline & $n$ & $\begin{array}{l}\text { Minor anomalies/clinical } \\
\text { manifestations }\end{array}$ \\
\hline \multirow[t]{15}{*}{ Group 1} & 1 & $\begin{array}{l}\text { Clinodactily in the } 5^{\circ} \text { finger } \\
\text { of the hand }\end{array}$ \\
\hline & 1 & Fold in the helix ear \\
\hline & 2 & Astigmatism; Myopia \\
\hline & 1 & Hypermetropia \\
\hline & 1 & $\begin{array}{l}\text { Hypopigmentation in } \\
\text { lumbar zone; Myopia }\end{array}$ \\
\hline & 1 & Anomalies finger printer \\
\hline & 1 & $\begin{array}{l}\text { Unpigmented spots } \\
\text { in the left leg }\end{array}$ \\
\hline & 1 & Myopia \\
\hline & 2 & Myopia \\
\hline & 1 & Myopia; Hypermetropia \\
\hline & 1 & $\begin{array}{l}\text { Myopia; Unpigmented spots } \\
\text { in the arms; Clinodactily in } \\
\text { the } 5^{\circ} \text { finger of the hand }\end{array}$ \\
\hline & 1 & $\begin{array}{l}\text { Congenital anomaly in the } \\
\text { right eye; Hyperconvex nails }\end{array}$ \\
\hline & 1 & Hyperconvex nails \\
\hline & 1 & Bifid uvula \\
\hline & 1 & $\begin{array}{l}\text { Parcial separation of the } \\
\text { uvula; Hypermetropia }\end{array}$ \\
\hline \multirow[t]{10}{*}{ Group 2} & 1 & Nasal septum defect \\
\hline & 2 & Astigmatism; Myopia \\
\hline & 1 & Umbilical hernia \\
\hline & 1 & $\begin{array}{l}\text { Hypertrophy in the right face; } \\
\text { Astigmatism and myopia; } \\
\text { Fissure in the ear (helix) }\end{array}$ \\
\hline & 1 & $\begin{array}{l}\text { Hypotrichosis in the eyebrows; } \\
\text { Nasal septum defect }\end{array}$ \\
\hline & 5 & Myopia \\
\hline & 1 & $\begin{array}{l}\text { Myopia dysplasia in the } \\
\text { right ear (helix); Anterior } \\
\text { tubercle in tragus }\end{array}$ \\
\hline & 1 & Myopia; Superfolded helix ear \\
\hline & 1 & Psoriasis \\
\hline & 1 & $\begin{array}{l}\text { Bilateral mandibular touros; } \\
\text { Pigmented spot in the lower lip }\end{array}$ \\
\hline \multirow[t]{8}{*}{ Group 3} & 1 & Astigmatism \\
\hline & 1 & Hypertrophy in the right face \\
\hline & 4 & Myopia \\
\hline & 1 & Miopia; Astigmatism \\
\hline & 1 & Myopia; Teleangiectasias \\
\hline & 1 & Ear protrusion \\
\hline & 1 & $\begin{array}{l}\text { Congenital cebaceous cist } \\
\text { in the right eye; Astigmatism }\end{array}$ \\
\hline & 1 & Retinoblastoma \\
\hline
\end{tabular}

\section{CONCLUSION}

There is an association between agenesis of the permanent maxillary lateral incisor and other tooth anomalies such as microdontia of the permanent maxillary lateral incisor, both in the individual and their relatives. Third molar absence is significantly more frequent in individuals with agenesis of the permanent maxillary lateral incisor. This might indicate a common genetic mechanism controlling these phenomena, influenced by several factors interacting at different levels.

Agenesis of teeth other than third molars was not significantly different between subjects with agenesis of the permanent maxillary lateral incisor and their relatives. However, if third molars are excluded, we found no other congenital absences in subjects with no agenesis of the permanent maxillary lateral incisor or family history of it.

Supernumerary teeth, maxillary canine inclusion, the general condition of health and minor anomalies were not appreciably different in the three groups.

The authors would like to thank the families who participated in this study. We are grateful to A. C. Braga for statistical support.

1. Aasheim B, Ogaard B. Hypodontia in 9-year-old Norwegians related to need of orthodontic treatment Scand I Dent Res 1993: 101: 257-260.

2. Baccetti T. A controlled study of associated dental anomalies. Angle Orthod 1998; 68: 267-274.

3. Endo T, Ozoe R, Kubota M, Akiyama M, Shimooka S. A survey of hypodontia in Japanese orthodontic patients. Am J Orthod Dentofacial Orthop 2006; 129: 29-35.

4. Horowitz J M. Aplasia and malocclusion: a survey and appraisal. Am J Orthod 1966; 52: 440-453.

5. Johannsdottir B, Wisth P J, Magnusson T E. Prevalence of malocclusion in 6-year-old Icelandic children. Acta Odontol Scand 1997; 55: 398-402.

6. Leitão P. Prevalência da má oclusão em crianças de 12 anos da cidade de Lisboa. Parte I. Rev Port Estomatol Cir Maxilofac 1993; 33: 193-201.

7. Maklin M, Dummett C O, Jr, Weinberg R. A study of oligodontia in a sample of New Orleans children. ASDC J Dent Child 1979; 46: 478-482.

8. Muller T P, Hill I N, Peterson A C, Blayney J R. A survey of congenitally missing permanent teeth J Am Dent Assoc 1970; 81: 101-107.

9. Pilo R, Kaffe I, Amir E, Sarnat H. Diagnosis of developmental dental anomalies using panoramic radiographs. ASDC J Dent Child 1987; 54: 267-272.

10. Rolling S. Hypodontia of permanent teeth in Danish schoolchildren. Scand J Dent Res 1980; 88: 365-369.

11. Thilander B, Myrberg N. The prevalence of malocclusion in Swedish schoolchildren. Scand J Dent Res 1973; 81: 12-21.

12. Helm S. Malocclusion in Danish children with adolescent dentition: an epidemiologic study. Am J Orthod 1968; 54: 352-366.

13. Magnusson T E. Prevalence of hypodontia and malformations of permanent teeth in Iceland. Community Dent Oral Epidemiol 1977; 5: 173-178.

14. Tavajohi-Kermani H, Kapur R, Sciote J J. Tooth agenesis and craniofacial morphology in an orthodontic population. Am J Orthod Dentofacial
Orthop 2002; 122: 39-47

15. Pinho T, Tavares $P$, Maciel P, Pollmann C Developmental absence of maxillary lateral incisor in the Portuguese population. Eur J Orthod 2005; 27: 443-449.

16. Bowden D E, Harrison J E. Missing anterior teeth: treatment options and their orthodontic implications. Dent Update 1994; 21: 428-434.

17. McNeill R W, Joondeph D R. Congenitally absent maxillary lateral incisor: treatment planning considerations. Angle Orthod 1973; 43: 24-29.

18. Tuverson D L. Orthodontic treatment using canines in place of missing maxillary lateral incisor. Am J Orthod 1970; 58: 109-127.

19. Hobkirk J A, Goodman J R, Jones S P. Presenting complaints and findings in a group of patients attending a hypodontia clinic. Br Dent J 1994: 177: 337-339

20. Bergendal B, Bergendal $T$, Hallonsten $A$ L, Koch $G$ et al. A multidisciplinary approach to oral rehabilitation with osseointegrated implants in children and adolescents with multiple aplasia. Eur J Orthod 1996: 18: 119-129.

21. Dhanrajani P J. Hypodontia: etiology, clinical features, and management. Quintessence Int 2002; 33: 294-302.

22. Millar B J, Taylor N G. Lateral thinking: the management of missing upper lateral incisor. Br Dent J 1995; 179: 99-106.

23. Taylor R W. Eruptive abnormalities in orthodontic treatment. Semin Orthod 1998; 4: 79-86.

24. Garn S M, Lewis A B. The gradient and the pattern of crown-size reduction in simple hypodontia. Angle Orthod 1970; 40: 51-58.

25. Schalk-van der Weide Y, Steen W H, Beemer FA, Bosman F. Reductions in size and left-right asymmetry of teeth in human oligodontia. Arch Oral Biol 1994; 39: 935-939.

26. Schalk-van der Weide Y, Bosman F. Tooth size in relatives of individuals with oligodontia. Arch Oral Biol 1996: 41: 469-472.

27. Baum B J, Cohen M M. Agenesis and tooth size in the permanent dentition. Angle Orthod 1971; 41: 100-102.

28. Becker A, Smith P, Behar R. The incidence of anomalous maxillary lateral incisor in relation to palatally-displaced cuspids. Angle Orthod 1981; 51:24-29.

29. Peck S, Peck L, Kataja M. Concomitant occurrence of canine malposition and tooth agenesis: evidence of orofacial genetic fields. Am J Orthod Dentofacial Orthop 2002; 122: 657-660.

30. Pirinen S, Arte S, Apajalahti S. Palatal displacement of canine is genetic and related to congenital absence of teeth. J Dent Res 1996: 75: 1742-1746

31. Zilberman $Y$, Cohen B, Becker A. Familial trends in palatal canines, anomalous lateral incisor, and related phenomena. Eur J Orthod 1990; 12: 135-139.

32. Brenchley Z, Oliver R G. Morphology of anterior teeth associated with displaced canines. Br J Orthod 1997: 24: 41-45.

33. Ranta R, Tulensalo T. Symmetry and combinations of hypodontia in non-cleft and cleft palate children. Scand J Dent Res 1988; 96: 1-8.

34. Zhu J F, Crevoisier R, Henry R J. Congenitally missing permanent lateral incisor in conjunction with a supernumerary tooth: case report. Pediatr Dent 1996; 18: 64-66.

35. Zhu J F, Marcushamer M, King D L, Henry R J. Supernumerary and congenitally absent teeth: a literature review. J Clin Pediatr Dent 1996; 20: 87-95.

36. Burzynski N J, Escobar V H. Classification and genetics of numeric anomalies of dentition. Birth Defects Orig Artic Ser 1983; 19: 95-106.

37. Marques A P F, Till M J. Ectodermal dysplasia: treatment considerations and case reports. Rev Port Cir Maxilofacial 1994; 35: 17-22.

38. Itthagarun A, King N M. Ectodermal dysplasia: a review and case report. Quintessence Int 1997; 28: 595-602.

39. Kobielak K, Kobielak A, Roszkiewicz J, Wierzba J et al. Mutations in the EDA gene in three unrelated families reveal no apparent correlation between phenotype and genotype in the patients with an 
$X$-linked anhidrotic ectodermal dysplasia. Am J Med Genet 2001; 100: 191-197.

40. Prabhu N T, John R, Munshi A K. Rieger's syndrome: a case report. Quintessence Int 1997; 28: 749-752.

41. Schalk-Van Der Weide Y, Beemer FA, Faber J A $J$, Bosman F. Symptomatology of patients with oligodontia. J Oral Rehabil 1994; 21: 247-261.

42. Proffit W R. Contemporary orthodontics. St. Louis: Mosby, 2007

43. Peck S, Peck L, Kataja M. Prevalence of tooth agenesis and peg-shaped maxillary lateral incisor associated with palatally displaced canine (PDC) anomaly. Am J Orthod Dentofacial Orthop 1996; 110: 441-443.

44. Gorgani N, Sullivan R E, DuBois L. A radiographic investigation of third-molar development ASDC J Dent Child 1990; 57: 106-110.

45. Gravely J F. A radiographic survey of third molar development. Br Dent J 1965; 119: 397-401.

46. Nik-Hussein N N, Abdul Majid Z. Dental anomalies in the primary dentition: distribution and correlation with the permanent dentition. J Clin Pediatr Dent 1996; 21: 15-19.

47. Nieminen $P$, Arte $S$, Pirinen S, Peltonen L, Thesleff I. Gene defect in hypodontia: exclusion of MSX1 and MSX2 as candidate genes. Hum Genet 1995; 96: 305-308.

48. Arte S, Nieminen P, Apajalahti S, Haavikko K et al. Characteristics of incisor-premolar hypodontia in families. J Dent Res 2001; 80: 1445-1450.

49. Svinhufvud E, Myllarniemi S, Norio R. Dominant inheritance of tooth malpositions and their association to hypodontia. Clin Genet 1988: 34: 373-381.

50. Kajii T S, Sato Y, Kajii S, Sugawara Y, Lida J. Agenesis of third molar germs depends on sagittal maxillary jaw dimensions in orthodontic patients in Japan. Angle Orthod 2004; 74: 337-342.

51. Peck S, Peck L, Kataja M. Site-specificity of tooth agenesis in subjects with maxillary canine malpositions. Angle Orthod 1996; 66: 473-476.
52. Segura J J, Hattab F, Rios V. Maxillary canine transpositions in two brothers and one sister: associated dental anomalies and genetic basis. ASDC J Dent Child 2002; 69: 54-58.

53. Vichi M, Franchi L. Eruption anomalies of the maxillary permanent cuspids in children with cleft lip and/ or palate. J Clin Pediatr Dent 1996; 20: 149-153.

54. Plunkett D J, Dysart P S, Kardos T B, Herbison G P. A study of transposed canines in a sample of orthodontic patients. Br J Orthod 1998; 25: 203-208.

55. Shapira Y, Kuftinec M M. Maxillary tooth transpositions: characteristic features and accompanying dental anomalies. Am J Orthod Dentofacial Orthop 2001; 119: 127-134.

56. Segura J J, Jimenez-Rubio A. Concomitant hypohyperdontia: simultaneous occurrence of a mesiodens and agenesis of a maxillary lateral incisor. Oral Surg Oral Med Oral Pathol Oral Radiol Endod 1998; 86: 473-475. 